Cancer Therapeutics: Experimental and Clinical Agents. p. 153-174. Humana Press, Totowa, NJ.

10.Pondarre, C., D. Strumberg, A. Fujimori, R. Torres-Leon and Y. Pommier. 1997. In vivo sequencing of camptothecin-induced topoisomerase I cleavage sites in human colon carcinoma cells. Nucleic Acids Res. 25:41114116.

11.Saluz, H. and J.-P. Jost. 1989. A simple highresolution procedure to study DNA methylation and in vivo DNA-protein interactions on a single-copy gene level in higher eukaryotes. Proc. Natl. Acad. Sci. USA 86:2602-2606.

12.Wang, J.C. 1996. DNA topoisomerases. Annu. Rev. Biochem. 65:635-692.

This work was supported in part by Associazione Italiana per la Ricerca sul Cancro, Milan, Italy. Address correspondence to Dr. Monica Binaschi, Menarini Ricerche, Via Tito Speri,10, 00040 Pomezia, Rome, Italy. Internet: pharmacology@menariniricerche.it

Received 5 November 1999; accepted 24 February 2000.

Monica Binaschi, Rosalba Farinosi, Maria E. Borgnetto and Giovanni Capranico Instituto Nationale per lo Studio e la Cura dei Tumori

Milan, Italy

\section{Using $B b v I$ and Related Restriction Enzymes to Cut DNA at Otherwise Inaccessible Sites}

BioTechniques 28:1066-1068 (June 2000)

In cloning, a desired DNA fragment is often difficult to obtain because of the reiteration of a particular restriction site. For example, isolation of the EcoRIHindIII fragment shown in Figure 1A would be difficult because of the presence of multiple internal HindIII sites. One solution to this problem would be to digest the DNA to completion with EcoRI, followed by incomplete digestion with HindIII and gel isolation of
Table 1. Partial List of the BbvI Class of Restriction Enzymes

\begin{tabular}{|c|c|c|c|}
\hline Enzyme & Recognition Site & Enzyme & Recognition Site \\
\hline \multirow[t]{2}{*}{$B b v l$} & $5^{\prime}-\mathrm{GCAGC}(\mathrm{N})_{8} \nabla$ & $B s m B I$ & $5^{\prime}$-CGTCTC $(\mathrm{N})_{1} \boldsymbol{\nabla}$ \\
\hline & $3^{\prime}-\mathrm{CGTCG}(\mathrm{N})_{12 \boldsymbol{\Delta}}$ & & $3^{\prime}-\mathrm{GCAGAG}(\mathrm{N})_{5 \boldsymbol{\Delta}}$ \\
\hline \multirow[t]{2}{*}{ Bpml } & $5^{\prime}-\mathrm{CTGGAG}(\mathrm{N})_{16} \boldsymbol{\nabla}$ & BsmFI & $5^{\prime}-\mathrm{GGGAC}(\mathrm{N})_{16} \boldsymbol{\nabla}$ \\
\hline & $3^{\prime}-\mathrm{GACCTC}(\mathrm{N})_{14 \boldsymbol{\Lambda}}$ & & $3^{\prime}-\mathrm{CCCTG}(\mathrm{N})_{14 \boldsymbol{A}}$ \\
\hline \multirow[t]{2}{*}{ Bsal } & $5^{\prime}-\mathrm{GGTCTC}(\mathrm{N})_{1} \boldsymbol{\nabla}$ & BspMl & $5^{\prime}-\mathrm{ACCTGC}(\mathrm{N})_{4} \boldsymbol{\nabla}$ \\
\hline & $3^{\prime}-\mathrm{CCAGAG}(\mathrm{N})_{5 \Delta}$ & & $3^{\prime}-T_{G G A C G}(N)_{8 \Delta}$ \\
\hline \multirow[t]{2}{*}{ BseRI } & $5^{\prime}-$ GAGGAG(N) ${ }_{10} \boldsymbol{\nabla}$ & BsrDI & 5'-GCAATGNN $\nabla$ \\
\hline & $3^{\prime}-\mathrm{CTCCTC}(\mathrm{N})_{8 \boldsymbol{\Delta}}$ & & $3^{\prime}-$ CGTTAC $_{\boldsymbol{\Delta}}$ \\
\hline \multirow[t]{2}{*}{$B s g l$} & $5^{\prime}-G_{T G C A G}(\mathrm{~N})_{16} \boldsymbol{\nabla}$ & Fokl & $5^{\prime}-\mathrm{GGATG}(\mathrm{N})_{9} \nabla$ \\
\hline & $3^{\prime}-\mathrm{CACGTC}(\mathrm{N})_{14 \boldsymbol{\Delta}}$ & & $3^{\prime}-\mathrm{CCTAC}(\mathrm{N})_{13 \boldsymbol{\Delta}}$ \\
\hline \multirow[t]{2}{*}{ BsmAl } & $5^{\prime}-\mathrm{GTCTC}(\mathrm{N})_{1} \nabla$ & SfaNI & $5^{\prime}-\mathrm{GCATC}(\mathrm{N})_{5}{ }^{\nabla}$ \\
\hline & $3^{\prime}-\mathrm{CAGAG}(\mathrm{N})_{5 \Delta}$ & & $3^{\prime}-\mathrm{CGTAG}(\mathrm{N})_{9 \Delta}$ \\
\hline
\end{tabular}

Cleavage sites are indicated by the arrowheads. $\mathrm{N}$ can be any base. Other enzymes of the Bbvl class give 1, 3 or 5-nucleotide overhangs. They are not shown here because they would not facilitate cloning into the polylinker sites of most common vectors.

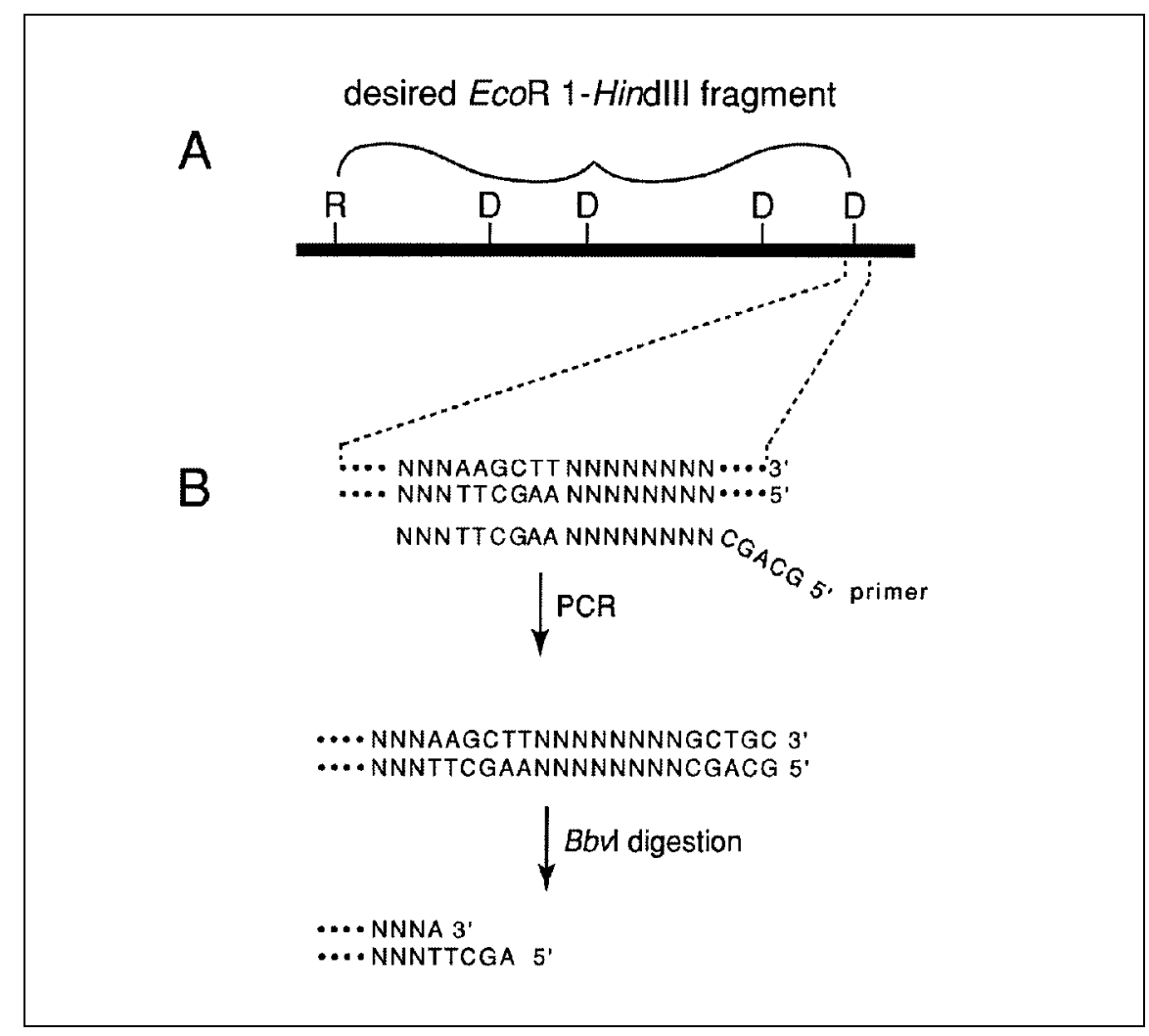

Figure 1. Specific cleavage at a non-unique restriction site. (A) Schematic representation of a DNA fragment containing a single EcoRI (R) restriction site and four HindIII (D) restriction sites. (B) Expanded view of the terminal HindIII site (recognition sequence $=5^{\prime}-\mathrm{A} \boldsymbol{\nabla}^{\mathrm{AGCTT}}$ ) and the sequence of a primer bearing a $B b v \mathrm{I}$ recognition sequence $\left(5^{\prime}-\mathrm{GCAGC}\right)$. The $3^{\prime}$ portion of this primer is complementary to the top strand of desired fragment. Note that with respect to the terminal HindIII site shown, digestion with $B b v I$ is equivalent to digestion with HindIII. The ability of Bbv to cut the terminal HindIII site is not affected by the identity of the bases (indicated with Ns) that flank the HindIII and BbvI sites. 
the desired fragment. Unfortunately, partial digests are difficult to control and are not feasible when the number of internal sites is high. A second solution would be to amplify the desired region with PCR using a primer set that flanks the terminal EcoRI and HindIII sites. In this case, a unique restriction site would be incorporated into the downstream primer in such a way that HindIII digestion would not be required for the cloning of the PCR product. Typically, this approach results in the addition of a portion of the primer sequence to the end (the HindIII-end in this case) of the desired DNA fragment. This would be problematic if, for example, one was trying to reconstitute an open reading frame (after subcloning of the PCR product into a vector) that ran through the terminal HindIII site.

Here, we present a class of restriction enzymes, referred to as the $B b v \mathrm{I}$ class, that permits specific cleavage of DNA at an otherwise non-unique restriction site. A partial list of such enzymes is shown in Table 1. All of the $B b v$ I class enzymes cut DNA outside of their recognition sequences. As illustrated in Figure $1 \mathrm{~B}$, the proximity of the $B b v \mathrm{I}$ recognition sequence to the terminal HindIII restriction site allows digestion with $B b v \mathrm{I}$ equivalent to that with HindIII. Note that the recognition sequence of $B b v \mathrm{I}$ and other enzymes of its class are non-palindromic. Thus, depending on the orientation of the recognition sequence within the primer, they are useful when incorporated into either the upstream or downstream primer for PCR. The non-palindromic nature of these recognition sequences also avoids problems associated with the inclusion of possible secondary structures into primers. The recognition sequences of most of the $B b v \mathrm{I}$ class enzymes are five or six nucleotides. With many such enzymes from which to choose, it should not be difficult to find one that is unique to the region of interest. The only obvious limitation of the $B b v$ I enzyme class is that it does not include any enzymes that give a fournucleotide $3^{\prime}$ overhang or a two-nucleotide $5^{\prime}$ overhang. Thus, these enzymes are not viable alternatives for cleavage of the recognition sites of PstI (5'-CT$\left.\mathrm{GCA}^{\boldsymbol{\nabla}} \mathrm{G}\right)$, ClaI $\left(5^{\prime}\right.$-AT $\left.\boldsymbol{\nabla}^{\mathbf{C G A T}}\right)$ and related enzymes.
Address correspondence to Dr. Robert $S$. Cohen, University of Kansas, Dept. of Molecular Biosciences, Division of Biology, $\mathrm{Ha}$ worth Hall, Lawrence, KS 66045-1630, USA. Internet:rscohen@falcon.cc.ukans.edu

Received 5 November 1999; accepted 17 January 2000.

\section{Robert S. Cohen \\ University of Kansas \\ Lawrence, KS, USA}

\section{Fluorescein PAGE Analysis of Microsatellite- Primed PCR: A Fast and Efficient Approach for Genomic Fingerprinting}

BioTechniques 28:1068-1072 (June 2000)

A simple but efficient DNA fingerprinting method is described. Microsatellite-anchored primers were labeled with fluorescein Cy5 and used for PCR amplification. The amplified fragments were detected on a denaturing polyacrylamide gel using an ALFexpress ${ }^{\mathrm{TM}}$ (Amersham Pharmacia Biotech, Uppsala, Sweden) automated DNA sequencer with the fragment option. High levels of polymorphism were detected at the intraspecific level, comparable with those detected with AFLP.

Microsatellite-primed PCR involves amplification of DNA using a single primer composed of a microsatellite sequence with 1-3 degenerate nucleotides anchored at the $3^{\prime}$ or $5^{\prime}$ end. The amplified fragments are termed inter-simple sequence repeats (ISSRs). As a new source of genetic markers, ISSR analysis combines advantages of RAPD (that is, no need for prior DNA sequence information) and the "standard" microsatellite analysis (that is, high-stringency annealing and thus more reproducible banding patterns). This PCR-based marker system has been ap- plied to reveal intra- and interspecific polymorphisms from a variety of eukaryotic taxa $(2,4)$. However, the number of loci detected using this method is usually much smaller than that detected with AFLP, although PAGE combined with silver staining can increase the resolution of the amplification products. Here, we describe a new microsatelliteprimed PCR method, in which Cy5 labeled primers were used for each PCR. The amplification products were separated in DNA sequencing gels, and the data were acquired with an ALFexpress automated DNA sequencer.

Genomic DNA from nine accessions of sweet potato (Ipomoea batatas (L) Lam.) was used in this study. Microsatellite primers $\mathrm{UBC} 807(\mathrm{AG})_{8} \mathrm{~T}$, $\mathrm{UBC} 888 \mathrm{BDB}(\mathrm{CA})_{7}$ and $\mathrm{UBC} 891$ $\mathrm{HVH}(\mathrm{TG})_{7}$ [abbreviations for degenerative base positions: $\mathrm{B}=(\mathrm{C}, \mathrm{G}$ and $\mathrm{T})$, $\mathrm{D}=(\mathrm{A}, \mathrm{G}$ and $\mathrm{T}), \mathrm{H}=(\mathrm{A}, \mathrm{C}$ and $\mathrm{T})$ and $\mathrm{V}=(\mathrm{A}, \mathrm{C}$ and $\mathrm{G})]$ were purchased from the Oligonucleotide Synthesis Laboratory, Nucleic Acid-Protein Service Unit, University of British Columbia, Vancouver, BC, Canada. The primers were $5^{\prime}$-end-labeled with fluorescein Cy5 (Amersham Pharmacia Biotech, Little Chalfont, UK). Amplification was carried out in a total volume of 25 $\mu \mathrm{L}$ containing $10 \mathrm{ng}$ template DNA, 30 ng labeled primers, $0.1 \mathrm{mM}$ dNTPs, 2 $\mathrm{mM} \mathrm{MgCl}_{2}, 0.75 \mathrm{U}$ Taq DNA polymerase (Promega, Madison, WI, USA) and $1 \times$ PCR buffer containing $50 \mathrm{mM}$ $\mathrm{KCl}, 10 \mathrm{mM}$ Tris- $\mathrm{HCl}(\mathrm{pH} 9.0)$ and $0.1 \%$ Triton $^{\circledR} \mathrm{X}-100$. PCR was performed using the following cycle profile: 1 cycle at $94^{\circ} \mathrm{C}$ for $5 \mathrm{~min}$, followed by 35 cycles of $94^{\circ} \mathrm{C}$ for $45 \mathrm{~s}, 51.5^{\circ} \mathrm{C}$ for $45 \mathrm{~s}$ and $72^{\circ} \mathrm{C}$ for $1.5 \mathrm{~min}$; and a final 7-min extension at $72^{\circ} \mathrm{C}$. Following $\mathrm{PCR}$, the products were mixed with an equal volume of formamide dye, and 7 $\mu \mathrm{L}$ were loaded on a $6 \%$ polyacrylamide sequencing gel. Data acquisition was performed with an ALFexpress automated sequencer using the fragment option. Results were analyzed by the software package DNA Fragment Manager version 1.2 (Amersham Pharmacia Biotech). A binary data matrix recording the presence or absence of the resulting bands was analyzed using PAUP* 4.0 (3) based on parsimony.

With two primer pairs $\mathrm{HVH}(\mathrm{TG})_{7}+$ $(\mathrm{AG})_{8} \mathrm{~T}$ and $\mathrm{BDB}(\mathrm{CA})_{7}+(\mathrm{AG})_{8} \mathrm{~T}$, the 